\title{
Impaired Renal Acidification in Infants with Fetal Alcohol Syndrome
}

\author{
FARAHNAK K. ASSADI AND MOHSEN ZIAI \\ University of Illinois Health Sciences (enter (F.K.A./, Chicago, Illinois 60612 and Georgetown University \\ Medical Center [M.Z.], Washington, D.C., 20007
}

\begin{abstract}
Urinary acidification was studied in six unrelated infants with fetal alcohol syndrome and eight healthy age-matched infants. Creatinine clearance, fractional sodium excretion, plasma renin activity, and plasma aldosterone were normal in all patients but fractional potassium excretion was lower in the patients than in the controls $(p=0.0001)$. After ammonium chloride loading, minimum urine pH was significantly higher in FAS patients than in control subjects $(5.5 \pm 0.1$ and $4.7 \pm 0.1$, respectively, $p=0.00005$ ). Net acid excretion was also lower in the patients $(24.5 \pm 1.7 \mathrm{Eq} / \mathrm{min})$ than in the controls $(27.8 \pm 2.1 \mathrm{Eq} / \mathrm{min}, p=0.008)$. Following sodium bicarbonate loading, fractional bicarbonate excretion was significantly higher $(p=0.00005)$ and fractional potassium excretion significantly lower $(p=0.002)$ in the patients than in the controls with comparable blood $\mathrm{pH}$ and bicarbonate levels. Treatment with chlorothiazide lowered plasma potassium and raised plasma bicarbonate to normal levels $(p=0.05)$. Concomitantly, fractional sodium excretion, fractional potassium excretion, and urinary net acid excretion increased significantly $(p=0.01)$. We conclude that patients with fetal alcohol syndrome have a defect in distal acidification and potassium excretion which cannot be attributed to abnormal aldosterone secretion. (Pediatr Res 19: 850-853, 1985)
\end{abstract}

\section{Abbreviations}

FAS, fetal alcohol syndrome

$\mathrm{FE}_{\mathrm{K}}$, fractional excretion of potassium

$\mathrm{PHCO}_{3}$, plasma bicarbonate concentration

$\mathrm{NH}_{4}$, ammonium

TA, titratable acid

NAE, net acid excretion

RTA, renal tubular acidosis

While evaluating patients with the FAS it became apparent that episodes of hyperchloremic metabolic acidosis associated with alkaline urine were common during the period of dehydration. Review of the literature showed no report of impaired renal acidification associated with the syndrome $(1-4)$. Therefore, a prospective study of renal acidification was performed in six infants with FAS to determine if there is any relationship between perinatal ethanol exposure and impaired urinary acidification in the development of metabolic acidosis.

Received January 14, 1985; accepted April 2, 1985

These studies were carried out at the Clinical Research Center at the University of Medical Sciences of Iran, supported by the Maternal and Child Public Health Service of Iranian National Institute of Health, and presented in part at the First International Medical Seminar in Iran. Tehran, November 1983.

\section{PATIENTS AND METHODS}

The subjects for this study were six infants selected from a larger prospective study on fetal dysmorphogenesis among alcoholic women. The mothers of the affected infants had been consuming alcohol heavily prior to and throughout pregnancy. None was addicted to any other drugs. All satisfied the criteria for alcoholism as defined by the criteria committee of the National Council on Alcoholism (5). The six selected infants of these women were recognized as having the pattern of altered growth and morphogenesis characteristic of FAS $(6,7)$. The pertinent clinical features shared by these children are shown in Table 1. All presented in early infancy with symptoms including poor feeding, vomiting, polyuria, dehydration, and failure to thrive. A pattern of impaired renal acidification aggravated by volume contraction was repeatedly noted in each patient. Fluid therapy improved this clinical condition and the acid-base disorder; however, hyperchloremic metabolic acidosis developed and persisted with each subsequent episode of dehydration. Normal blood concentrations of glucose, calcium, phosphate, and alkaline phosphatase were obtained in all patients. Blood pressure measurements taken on several occasions were normal. None had malabsorption syndromes, glucosuria, aminoaciduria, proteinuria, hyperphosphaturia (defined as tubular reabsorption of phosphate $85 \%$ ), or hypercalciuria (urine calcium/urine creatinine 0.25 ). Intravenous pyelography and renal ultrasonography disclosed no abnormalities. Most infants were fed a combination of breast milk, commercial formula, and cereals, providing an average daily caloric intake of 105 (range 100-110) kcal/ $\mathrm{kg}$ at the time of study.

Studies of renal function were performed when the patients were clinically stable in the absence of dehydration. Eight healthy age-matched infants were similarly studied and served as controls. Although the normal infants were larger than the FAS infants, group mean values for weight were not significantly different. The average weight was $7.18 \mathrm{~kg}$ in the infants with FAS and $7.21 \mathrm{~kg}$ in the control group. All the urines were collected under mineral oil for $5 \mathrm{hr}$ by means of bladder catheterization. Ten-milliliter aliquots of urine were then aspirated under oil in an air-tight syringe, and the $\mathrm{pH}, \mathrm{NH}_{4}$, and TA were measured within $5 \mathrm{~min}$ of collection. Arterialized capillary blood samples were obtained at the midpoint of each urine collection. In both blood and urine specimens, $\mathrm{pH}$ determinations were made using direct-reading electrodes on a Mark 2 Digital AcidBase Analyzer (Radiometer, Copenhagen, Denmark). Urinary acidification was studied using the short ammonium chloride test of Edelmann et al. $(8,9)$. Urinary $\mathrm{NH}_{4}, \mathrm{TA}, \mathrm{NAE}$, and bicarbonate were analyzed by methods previously described $(10$, 11). Alkalinization of the urine was accomplished in all infants using the standard protocols of the bicarbonate titration test (12). Creatinine content of plasma and urine was measured with a Beckman Creatinine Analyzer 2. Sodium and potassium were measured by flame photometry. Glomerular filtration rate was 
Table 1. Clinical features observed in infants with the FAS

\begin{tabular}{|c|c|c|c|c|c|c|}
\hline \multirow[b]{2}{*}{ Feature } & \multicolumn{6}{|c|}{ Patient } \\
\hline & 1 & 2 & 3 & 4 & 5 & 6 \\
\hline Age (mo)/sex & $12 / \mathrm{F}$ & $10 / \mathrm{F}$ & $10 / \mathrm{M}$ & $8 / \mathrm{F}$ & $7 / \mathrm{F}$ & $6 / \mathrm{M}$ \\
\hline \multicolumn{7}{|c|}{ Growth deficiency (10th percentile) } \\
\hline Prenatal & + & + & + & + & + & + \\
\hline Postnatal & + & + & + & + & + & + \\
\hline \multicolumn{7}{|l|}{ Facial characteristics } \\
\hline Short palpebral fissures & + & + & + & + & + & + \\
\hline Hypoplastic philtrum & + & + & - & + & + & + \\
\hline Hypoplastic maxilla & + & + & + & + & - & - \\
\hline Microcephaly (3rd percentile) & + & - & + & + & + & + \\
\hline \multicolumn{7}{|l|}{ Centra! nervous system } \\
\hline Developmental delay & + & + & + & + & + & + \\
\hline Hypotonia & - & - & + & - & + & - \\
\hline \multicolumn{7}{|l|}{ Skeletal } \\
\hline Joint anomalies & - & - & - & $t^{*}$ & - & - \\
\hline Altered plamar crease pattern & - & + & - & - & - & - \\
\hline Cardiac anomaly & - & - & - & - & $+t$ & - \\
\hline
\end{tabular}

* Syndactyly of the second and third toes bilaterally and limitation of motion at elbows.

$\dagger$ Atrial septal defect.

estimated by clearance of endogenous creatinine (urinary concentration of creatinine times urinary flow rate)/plasma concentration of creatinine. The fractional excretion of a substance was calculated according to the standard formula (clearance of the substance/creatinine clearance $\times 100$ ). Fasting and supine plasma renin activity was measured by radioimmunoassay $(E$. R. Squibb and Sons, Inc., Princeton, NJ). Plasma aldosterone was determined using a standard radioimmunoassay kit (Diagnostic Products Corp., Los Angeles, CA).

The possibility of a primary defect in potassium excretion was explored by examining the urinary acidification following oral diuretic therapy (13). Chlorothiazide, $10 \mathrm{mg} / \mathrm{kg} / \mathrm{day}$, was administered orally for a period of 5 days. Before and after this diuretic agent, timed urine collections and blood samples were obtained. The specimens were analyzed for bicarbonate, $\mathrm{pH}$, sodium, potassium, $\mathrm{NH}_{4}$, and TA. The protocol for this study was approved by the Institutional Review Board, the University of Medical Science of Iran, and informed written maternal consent was obtained for all patients prior to study. Statistical analysis was done using the Student's $t$ test for paired or unpaired variables. All values represent the mean $\pm \mathrm{SD}$.

\section{RESULTS}

Initial biochemical data in FAS patients are summarized in Table 2. Baseline $\mathrm{FE}_{\mathrm{K}}$ in FAS group was significantly lower than the control group $(p=0.0001)$. Clearance of creatinine, plasma concentrations of aldosterone, plasma renin activity, and fractional excretion of sodium were normal in all subjects.

After ammonium chloride loading the urine $\mathrm{pH}$ fell significantly in both patient and control subjects (Table 3). Urine $\mathrm{pH}$ fell below 5.5 in only one of the six FAS infants with a mean decrease of the group to $5.5 \pm 0.1$. This was significantly higher than the minimum urinary $\mathrm{pH}$ in eight control subjects in whom urinary $\mathrm{pH}$ after acid loading was $4.7 \pm 0.1,(p=0.00005)$. In all of the control subjects urine pH fell to 4.8 or less. The fall in $\mathrm{PHCO}_{3}$ was more pronounced in patients than in controls. Maximum $\mathrm{NH}_{4}$ excretion $(p=0.0002)$ and net acid excretion $(p=0.008)$ were lower in FAS patients than in controls. TA accounted for a higher percentage of NAE in FAS subjects compared to control subjects $(52 \pm 0.3$ and $47 \pm 0.7$, respectively) $(p<0.05)$. FE $\mathrm{K}_{\mathrm{K}}$ was significantly lower $(p=.00005)$ in FAS patients compared to the controls.

When urinary bicarbonate excretion was studied at normal $\mathrm{PHCO}_{3}$ concentration, FAS patients excreted a higher percentage of the filtered load than in controls $(p=0.00005$, Table 4)
Table 2. Initial laboratory data in six infants with FAS (mean

\begin{tabular}{lrc} 
& \multicolumn{3}{c}{ $\pm S D)^{*}$} \\
\hline & \multicolumn{1}{c}{ Control } & \multicolumn{1}{c}{ FAS } \\
\hline Urine $\mathrm{pH}$ & $5.9 \pm 0.1$ & $6.0 \pm 0.3$ \\
Plasma pH & $7.36 \pm 0.1$ & $7.35 \pm 0.1$ \\
$\mathrm{PHCO}_{3}(\mathrm{mEq} / \mathrm{liter})$ & $21 \pm 0.5$ & $20.9 \pm 0.4$ \\
$\mathrm{PK}(\mathrm{mEq} / \mathrm{liter})$ & $5.3 \pm 0.1$ & $5.4 \pm 0.1$ \\
$\mathrm{C}_{\mathrm{Cr}}(\mathrm{ml} / \mathrm{min})$ & $22.5 \pm 2.8$ & $22 \pm 2.5$ \\
$\mathrm{FE}_{\mathrm{K}}(\%)$ & $28 \pm 1.8$ & $23 \pm 1.3 \dagger$ \\
$\mathrm{FE}_{\mathrm{Na}}(\%)$ & $0.4 \pm 0.1$ & $0.5 \pm 0.1$ \\
$\mathrm{PRA}(\mathrm{ng} / \mathrm{ml} / \mathrm{h})$ & $7.8 \pm 0.7$ & $7.9 \pm 0.8$ \\
$\mathrm{Plasma}$ aldo $(\mathrm{g} / \mathrm{dl})$ & $60 \pm 5$ & $62 \pm 6$ \\
\hline
\end{tabular}

*Abbreviations: PK. plasma potassium; $\mathrm{C}_{\mathrm{Cr}}$, creatinine clearance; $\mathrm{FE}_{\mathrm{Na}}$, fractional sodium excretion; aldo, aldosterone.

$\dagger p=0.0001$.

Table 3. Results of acidification in response to ammonium chloride administration (mean $\pm S D)^{*}$

\begin{tabular}{lrcc}
\hline & Controls & \multicolumn{1}{c}{ FAS } & \multicolumn{1}{c}{$p \dagger$} \\
\hline Urine $\mathrm{pH}$ & $4.7 \pm 0.1$ & $5.5 \pm 0.1$ & 0.00005 \\
Plasma $\mathrm{pH}$ & $7.33 \pm 0.1$ & $7.32 \pm 0.1$ & $\mathrm{NS} \ddagger$ \\
$\mathrm{PHCO}_{3}(\mathrm{mEq} / \mathrm{liter})$ & $16.7 \pm 0.4$ & $15.8 \pm 0.2$ & 0.0003 \\
$\mathrm{PK}(\mathrm{mEq} / \mathrm{liter})$ & $5.3 \pm 0.2$ & $5.5 \pm 0.2$ & $\mathrm{NS}$ \\
$\mathrm{FE}$ & $29 \pm 1.6$ & $23.5 \pm 1.3$ & 0.00005 \\
$\mathrm{U}_{\mathrm{NH}} \mathrm{V}(\mathrm{Eq} / \mathrm{min})$ & $14.3 \pm 1.0$ & $11.7 \pm 0.8$ & 0.0002 \\
$\mathrm{U}_{\mathrm{TA}} \mathrm{V}(\mathrm{Eq} / \mathrm{min})$ & $13.5 \pm 1.1$ & $12.8 \pm 0.9$ & $\mathrm{NS}$ \\
$\mathrm{U}_{\mathrm{NAE}} \mathrm{V}(\mathrm{Eq} / \mathrm{min})$ & $27.8 \pm 2.1$ & $24.5 \pm 1.7$ & 0.008 \\
\hline
\end{tabular}

* Abbreviations: $\mathrm{PK}$, plasma potassium; $U_{\mathrm{NH} 4} \mathrm{~V}$, urinary ammonium excretion; $U_{T A} V$, urinary titratable acid excretion; $U_{\mathrm{NAE}} \mathrm{V}$, urinary net acid excretion.

† Unpaired $t$ test.

$\$$ Not significant $(p>0.05)$.

Table 4. Summary of data following bicarbonate titration tests $(\text { mean } \pm S D)^{*}$

\begin{tabular}{lrcc}
\hline & \multicolumn{1}{c}{ Controls } & \multicolumn{1}{c}{ FAS } & \multicolumn{1}{c}{$p \dagger$} \\
\hline Urine $\mathrm{pH}$ & $7.39 \pm 0.1$ & $7.40 \pm 0.2$ & $\mathrm{NS} \ddagger$ \\
Plasma $\mathrm{pH}$ & $7.38 \pm 0.1$ & $7.37 \pm 0.1$ & $\mathrm{NS}$ \\
$\mathrm{PHCO}_{3}(\mathrm{mEq} / \mathrm{liter})$ & $23.1 \pm 0.1$ & $22.8 \pm 0.3$ & $\mathrm{NS}$ \\
$\mathrm{PK}(\mathrm{mEq} / \mathrm{liter})$ & $5.1 \pm 0.2$ & $5.2 \pm 0.1$ & $\mathrm{NS}$ \\
$\mathrm{FE}_{\mathrm{K}}(\%)$ & $32.5 \pm 3.5$ & $26 \pm 1.0$ & 0.002 \\
$\mathrm{FE}_{\mathrm{HCO}}(\%)$ & $0.8 \pm 0.1$ & $3.5 \pm 0.2$ & 0.00005 \\
$\mathrm{FE}_{\mathrm{Na}}(\%)$ & $1.3 \pm 0.2$ & $1.5 \pm 0.1$ & $\mathrm{NS}$ \\
\hline
\end{tabular}

*Abbreviations: PK, plasma potassium; $\mathrm{FE}_{\mathrm{Na}}$, fractional sodium excretion.

t Unpaired $t$ test.

$\$$ Not significant $(p>0.05)$.

indicating a mild to moderate bicarbonate leak in FAS subjects. During bicarbonate loading, $\mathrm{FE}_{\mathrm{K}}$ was again significantly lower in patients than in controls.

Treatment with chlorothiazide lowered plasma potassium and raised $\mathrm{PHCO}_{3}$ (Table 5). Concomitantly, fractional excretion of sodium, $\mathrm{FE}_{\mathrm{K}}$, and NAE increased and urinary $\mathrm{pH}$ decreased significantly. The percentage of $\mathrm{NH}_{4}$ excreted during diuretic therapy was higher than urinary TA excretion ( $50 \pm 0.6$ and 49 $\pm 0.4 \%$, respectively).

\section{DISCUSSION}

The results of our study demonstrate the presence of tubular dysfunction in patients with FAS despite preservation of normal glomerular function. Five of six patients were unable to lower their urine $\mathrm{pH}$ to less than 5.5, and all six had a blunted increase in urinary excretion of $\mathrm{TA}$ and $\mathrm{NH}_{4}$ in response to ammonium 
Table 5. Effect of chlorothiazide on renal acidification in six infants with FAS (mean $\pm S D)^{*}$

\begin{tabular}{|c|c|c|c|}
\hline & \multicolumn{2}{|c|}{ Chlorothiazide therapy } & \multirow[b]{2}{*}{$p \dagger$} \\
\hline & Before & After & \\
\hline Wt $(\mathrm{kg})$ & $7.18 \pm 1.6$ & $7.10 \pm 1.5$ & NS \\
\hline Urine $\mathrm{pH}$ & $6.1 \pm 0.1$ & $5.0 \pm 0.1$ & 0.05 \\
\hline Plasma pH & $7.34 \pm 0.1$ & $7.36 \pm 0.1$ & 0.05 \\
\hline $\mathrm{PHCO}_{3}(\mathrm{mEq} /$ liter $)$ & $21 \pm 0.1$ & $22 \pm 0.5$ & 0.05 \\
\hline $\mathrm{PK}$ (mEq/liter) & $5.5 \pm 0.2$ & $5.1 \pm 0.1$ & 0.01 \\
\hline $\mathrm{FE}_{\mathrm{K}}(\%)$ & $21 \pm 1.5$ & $27.2 \pm 1.1$ & 0.001 \\
\hline $\mathrm{FE}_{\mathrm{Na}}(\%)$ & $0.4 \pm 0.1$ & $4.9 \pm 0.2$ & 0.00001 \\
\hline $\mathrm{U}_{\mathrm{NH} 4} \mathrm{~V}(\mathrm{Eq} / \mathrm{min})$ & $11.5 \pm 0.2$ & $12.9 \pm 0.5$ & 0.01 \\
\hline$U_{T A} V(E q / m i n)$ & $12.1 \pm 0.1$ & $13.2 \pm 0.4$ & 0.05 \\
\hline $\mathrm{U}_{\mathrm{NAE}} \mathrm{V}(\mathrm{Eq} / \mathrm{min})$ & $23.6 \pm 0.3$ & $26.1 \pm 0.9$ & 0.01 \\
\hline
\end{tabular}

* Abbreviations: PK, plasma potassium; $\mathrm{FE}_{\mathrm{Na}}$, fractional sodium excretion; $U_{N H 4} V$, urinary ammonium excretion; $U_{T A} V$, urinary titratable acid excretion: $U_{\mathrm{NAE}} \mathrm{V}$, urinary net acid excretion.

$\dagger$ Paired $l$ test.

chloride administration. During bicarbonate infusion, the amount of bicarbonate excreted in the urine at normal $\mathrm{PHCO}_{3}$ remained below $5 \%$ in all six FAS patients. These findings are characteristics of distal rather than proximal RTA $(9,14,15)$. Because $\mathrm{PHCO}_{3}$ concentrations and blood $\mathrm{pH}$ were normal prior to the acid loading, the inability to lower urine $\mathrm{pH}$ in our patients is consistent with incomplete distal RTA (16). In patients with incomplete distal $\mathrm{RTA}, \mathrm{NH}_{4}$ excretion characteristically constitutes a greater than normal fraction of urinary acid both before and during induced acidosis (16). In our patients with FAS NH excretion presented a smaller fraction of total acid produced, and the absolute excretion was also lower than that observed in control subjects. Since $\mathrm{NH}_{4}$ excretion and final acidification occur primarily in the collecting duct (17), the impairment of this aspect of tubular function might be expected in FAS patients.

All of our patients with FAS also had an abnormality in tubular secretion of potassium. Despite the impairment in renal potassium excretion, hyperkalemia did not develop during acid load. ing, suggesting the presence of an extrarenal mechanism of potassium adaptation (18). Since urinary potassium excretion primarily reflects secretion in the distal nephron, probably at the level of the cortical collecting duct $(19,20)$, the decreased $F E_{K}$ is further evidence for a distal tubular dysfunction in FAS patients.

Defective potassium excretion can result from decreased delivery of sodium to the distal nephron $(21-23)$, a defect in aldosterone secretion (24-26), or a primary defect in tubular secretion of potassium $(27-29)$. Decreased sodium delivery to the distal nephron cannot account for the impairment in urinary potassium excretion observed in FAS patients. As shown in Table 4, our patients were able to increase urinary sodium excretion in response to sodium bicarbonate administration, but their ability to augment potassium excretion was markedly decreased compared to control subjects suggesting a defect in distal sodium reabsorption.

Since hyporeninemic hypoaldosteronism can result in renal acidosis and impaired potassium excretion (24-26), the integrity of the renin-aldosterone axis was examined in FAS infants. The results demonstrated normal values for plasma renin activity and plasma aldosterone concentration (Table 2), thus excluding hypoaldosteronism as the cause of the impaired potassium excretion.

Having dismissed hypoaldosteronism as the cause of the impaired potassium excretion, we had to consider the possibility of primary defect in potassium secretion in FAS patients. To examine this possibility, each subject was treated with chlorothiazide. Thiazides are known to enhance potassium excretion by increasing tubular flow rate, providing more sodium to the distal sodium-potassium exchange sites and causing volume depletion with concomitant stimulation of aldosterone secretion (13). Ad- ministration of chlorothiazide produced marked diuresis of both sodium and potassium. Plasma potassium decreased and $\mathrm{PHCO}_{3}$ rose to normal levels. Concomitantly NAE increased significantly. It is unlikely that this effect was due to extracellular volume contraction, since the change in body weight at this point was negligible. Therefore, it seems logical to speculate that the kaliuretic and acidification response to chlorothiazide in our FAS patients was the consequence of enhanced sodium delivery to the cation-exchange sites in the distal nephron where aldosterone exerts its effect $(19,20)$.

In the presence of sufficient mineralocorticoid activity, an increase in distal delivery of sodium increases the normally observed lumen-negative potential difference $(27,28)$. This increase in potential difference then promotes hydrogen ion secretion. Since distal potassium secretion is also dependent on the lumen-negative potential difference created by sodium reasorption $(19,20)$, the urinary potassium excretion would similarly be increased. A defect in sodium reabsorption at the distal nephron would result in a decreased potential difference, and hence in a decrease in urinary acidification (27-30).

The findings of the combined tubular defects in distal acidification and potassium excretion in the presence of adequate levels of plasma aldosterone and inability to lower the urine $\mathrm{pH}$ during acidemia are consistent with a voltage-dependent type of distal RTA $(29,30)$. Such patients are also recognized by inability to lower urine $\mathrm{pH}$ and to increase potassium excretion in response to maneuvers which enhance lumen-oriented electro-negativity in the distal nephron $(31,32)$. While we did not infuse $\mathrm{Na}_{2} \mathrm{SO}_{4}$ to our patients, the fall in urine $\mathrm{pH}$ and the increase in potassium excretion observed after chlorothiazide administration rather suggests that our patients had a reversible type of voltage-dependent distal RTA (30). The resulting hyperchloremic metabolic acidosis in this variant of distal RTA is distinguished from that of type 4 RTA by the accompanying normal plasma aldosterone concentration $(33,34)$.

The similarity in the present study in the pattern of impaired hydrogen ion and potassium excretion among the patients with FAS, suggest a singular mode of etiology. Intrinsic damage to the cells of the distal nephron caused by ethanol appears to be the most likely possibility. However, further studies will be needed to determine the pathophysiologic mechanisms responsible for the impaired renal acidification in FAS patients. Regardless of the mechanism, FAS should be added to the list of conditions associated with secondary RTA.

Acknowledgments. The authors are especially grateful to the medical students and the nursing staff of the University of Medical Sciences of Iran, whose efforts and understanding made possible the accumulation of much of these data. We thank Dr. Pedro Jose for reviewing the manuscript, and Miss Gerald Gardner for secretarial help.

\section{REFERENCES}

1. Hanson JW, Jones KL, Smith DW 1976 Fetal alcohol syndrome, experience with 41 patients. JAMA 235:1458-1460

2. Oullette EM, Rosett HL, Rosman NP, Weiner L 1977 Adverse effects on offspring of maternal alcohol abuse during pregnancy. $N$ Engl $J$ Med 297:528-530

3. Streissguth AP, Landesman-Dwyer S, Martin JC, Smith DW 1980 Teratogenic effects of alcohol in humans and laboratory animals. Science 209:353-361

4. Clarren SK, Smith DW 1978 The fetal alcohol syndrome. N Engl $J$ Med 298:1063-1067

5. Criteria for the diagnosis of alcoholism, 1972 Criteria Committee, Nationa? Council on Alcoholism. Anr. Intern Med 77:249-258

6. Jones KL, Smith DW 1973 Recognition of the fetal alcohol syndrome in early infancy. Lancet 2:999-1001

7. Jones KL, Smith DW, Ulleland CN, Streissguth AP 1973 Pattern of malformation in offspring of chronic alcoholic mothers. Lancet 1:1267-1271

8. Edelmann CM Jr, Boichis H, Rodriguez-Soriano J, Stark H 1967 The renal response of children to acute ammonium chloride acidosis. Pediatr Res $1: 452-460$

9. Edelmann CM Jr, Rodriguez-Soriano J, Boichis $\mathrm{H}$, Gruskin AB, Acosta M 1967 Renal bicarbonate reabsorption and hydrogen ion excretion in normal infants. J Clin Invest 46:1309-1317 
10. Chan JCM 1972 The rapid determination of urinary titratable acid and ammonium and evaluation of freczing as a method of preservation. Clin Biochem 5:94-98

11. Lin SL, Chan JCM 1973 Urinary bicarbonate. A tirrimetric method for determination. Clin Biochem 6:207-210

12. Broyer M 1974 Bicarbonate titration. In: Royer P. Habib R, Mathieu H, Broyer M, Walsh A (eds) Pediatric Nephrology. WB Saunders Company, Philadelphia, pp 427-428

13. Gicbish $G 1976$ Effect of diuretics on renal transport of potassium. In Martinez-maldonado M (ed) Methods in Pharmacology. Plenum Press, New York, pp 121-164

14. McSherry E 1981 Renal tubular acidosis in childhood. Kidney Int 20:799-809

15. Morris RC Sebastian A, McSherry E 1971 Renal acidosis. Kidney Int 1:327340

16. Tannen RL, Falls WE, Brackett NC 1975 Incomplete renal tubular acidosis: Some clinical and physiological features. Nephron 15:111-113

17. Rector FC 1976 Renal acidification and ammonia production. In: Brenner BM, Rector FC (eds) The Kidney. WB Saunders Company, Philadelphia, pp 318-343

18. Alexander EA, Levinsky NG 1968 An external mechanism of potassium excretion. J Clin Invest 47:740-748

19. Stokes JB 1982 lon transport by the cortical and outer medullary collecting tubule. Kidney Int 22:473-484

20. Koeppen B. Helman SI 1982 Acidification of luminal fluid by the rabbit cortical collecting tubule perfused in vitro. Am J Physiol 242:F52 I-F531

21. Maline G, Klose RM, Giebisch G 1966 Micropuncture study of distal tubular potassium and sodium transport in the rat kidney. Am J Physiol 211:529547

22. Howell DS, Davis JO 1954 Relationship of sodium retention to potassium excretion by the kidney during administration of desoxycorticosterone acetate to dogs. Am J Physiol 179:359-363
23. Wright FS 1971 Increasing magnitude of electrical potential along the renal distal tubule. Am J Physiol 220:624-638

24. Batle DC 1981 Hyperkalemic hyperchloremic metabolic acidosis associated with selective aldosterone deficiency and distal renal tubular acidosis. Semin Nephrol 1:260-274

25. Kurtzman NA, White MG, Rogers PW 1971 Aldosterone deficiency and renal bicarbonate reabsorption. J Lab Clin Med 77:931-939

26. Batle DC, Sehy JT, Roseman MK, Arruda JAL, Kurtzman NA 1981 Clinical and pathophysiologic spectrum of acquired distal renal tubular acidosis. Kidney Int 20:389-396

27. Arruda JAL, Kurtzman NA 1980 Mechanisms and classification of deranged distal urinary acidification. Am J Physiol 239:F515-F523

28. Batlle DC, Sehy JT, Roseman MK, Arruda JAL, Kurtzman NA 1981 Clinical and pathophysiologic spectrum of acquired distal renal tubular acidosis. Kidney Int 20:389-396

29. Batlle DC, Arruda JAL, Kuntzman NA 1981 Hyperkalemic distal renal tubula acidosis associated with obstructive uropathy. N Engl J Med 304:373-380

30. Batlle DC, Istarayovngyuen K, Arruda JAL, Kurtzman NA 1982 Hyperkalemi hyperchloremic metabolic acidosis in sickle cell hemoglobinopathies. Am J Med 72:188-192

31. Arruda JAL, Dytko G, Mola R, Kurtzman NA 1980 On the mechanism of lithium-induced distal renal tubular acidosis: studies in the turtle bladder. Kidney Int 17:196-204

32. Amuda JAL, Subbarayudu K, Dytko G, Mola R, Kurtzman NA 1980 Voltage: dependent distal acidification defect induced by amiloride. J Lab Clin Med 95:407-416

33. Steinbaugh BJ, Schloeder FX, Tam SC, Goldstein MB, Halperin ML 198 Pathogenesis of distal renal tubular acidosis. Kidney Int 19:1-7

34. Sebastian A, Hulter HN, Schambelan M 1978 Renal hyperchloremic acidosis with hyperkalemia, type 4 renal tubular acidosis. In: Proceedings of the VIIth International Congress of Nephrology, pp 351-360

\title{
Epidermal Growth Factor in Mouse Milk during Early Lactation: Lack of Dependency on Submandibular Glands
}

\author{
A. GRUETERS, J. ALM, J. LAKSHMANAN, AND D. A. FISHER
}

Department of Pediatrics, Harbor-UCLA Medical Center, Torrance, California 90509

\begin{abstract}
Using a specific and sensitive radioimmunoassay, we found epidermal growth factor (EGF) in mouse milk during early lactation in normal and sialoadenectomized mice. Levels of EGF peaked around the 6th day postpartum and decreased thereafter up to day 12 . Sephadex G-50 column chromatography of milk from normal and sialoadenectomized mice showed a single immunoreative component comigrating with purified 6045 dalton EGF from the mouse submandibular gland. The concentrations of EGF were similar in milk collected from the breast and the stomach of the offspring immediately after feeding. The molecular profiles, concentrations, and ontogeny of EGF in milk of control and sialoadenectomized mice were also similar, suggesting that the submandibular gland is
\end{abstract}

Received January 7, 1985; accepted April 2, 1985.

Request for reprints should be addressed to Dr. A. Grueters, University Chil dren's Hospital, Kavh Heubnerweg 6, D-1000 Berlin, FRG.

Supported by the National Institute of Health Grants HD-04270 (D.A.F.) and NS-17431A (J.L.). At the time of this study, A.G. was a research fellow of the Department of Pediatrics, Harbor-UCLA Medical Center and J.A. was a recipient of stipends from the UCLA-Silbert International Scholars Program and Savstahomsforeningen Sweden. not the major source of EGF in mouse breast milk. (Pediatr Res 19: 853-856, 1985)

\section{Abbreviations}

EGF, epidermal growth factor

SMG, submandibular gland

RIA, radioimmunoassay

PBS, phosphate-buffered saline

EGF is present ion high concentrations in mouse $S M G$ and in lesser concentrations in many mouse and human tissues and body fluids (1-5). EGF stimulates accelerated proliferation and differentiation of skin, corneal epithelium, and lung tissue in vitro and induces a cascade of events that results in increased mitogenic activity. In vivo EGF accelerates eyelid opening and tooth eruption in newborn mice (6), and promotes functional maturation of the intestine (7) and lungs (8). Functional EGF receptors have been found in many embryonic tissues (9). 